\title{
Watermelon Germplasm Lines USVL246-FR2 and USVL252-FR2 Tolerant to Fusarium oxysporum f. sp. niveum Race 2
}

\author{
W. Patrick Wechter ${ }^{1,2}$, Melanie M. McMillan, Mark W. Farnham, \\ and Amnon Levi \\ U.S. Vegetable Laboratory, Agricultural Research Service, U.S. Department \\ of Agriculture, 2700 Savannah Highway, Charleston, SC 29414
}

Additional index words. Citrullus citroides, inbred line, host plant resistance

Two improved germplasm lines of wild watermelon (Citrullus lanatus var. citroides) designated USVL246-FR2 and USVL252FR2 were released in 2012 by the Agricultural Research Service of the U.S. Department of Agriculture (Wechter et al., 2012). These lines are each highly uniform for growth characteristics, fruit size, and fruit shape. In both greenhouse and field tests, these lines also exhibit high levels of tolerance to the phytopathogen Fusarium oxysporum f. sp. niveum race 2 (Fon-R2) when compared with the watermelon cultivars Charleston Gray, Allsweet, Calhoun Gray, and Sugar Baby (all C. lanatus var. lanatus). In addition, they have shown higher vigor and equal or higher tolerance levels to Fon-R2 than PI 296341-FR, an improved C. lanatus var. citroides germplasm line derived from U.S. PI 296341, which has been reported previously as resistant to Fon-R2 (Martyn and Netzer, 1991)

Fusarium wilt [caused by $F$. oxysporum Schlechtend.:Fr. f. sp. niveum (E.F. Sm.) W.C. Snyder \& H.N. Hans (Fon)] is one of the most serious soilborne diseases of watermelon (Martyn, 1985, 1987; Netzer, 1976). There are four pathogenic races, $0,1,2$, and 3 (Martyn and Netzer, 1991; Netzer, 1976; Netzer and Martyn, 1989; Zhou et al., 2010). Various commercial cultivars have been introgressed with resistance to Fon race 0 and 1 , but not to race 2 or 3 . Fon-R 2 has been reported throughout the United States (Bruton and Damicone, 1999; Bruton et al., 1988, 2008; Egel et al., 2005; Keinath and DuBose, 2009; Martyn, 1985; Martyn and Bruton, 1989; Zhou and Everts, 2001, 2003). Fusarium wilt can reduce yield of susceptible watermelon by $40 \%$ (Keinath et al., 2010).

USVL246-FR2 and USVL252-FR2 were developed at the U.S. Vegetable Laboratory, Charleston, SC. The PIs from which the released lines were developed, PI 482246

\footnotetext{
Received for publication 29 Sept. 2015. Accepted for publication 23 Dec. 2015.

${ }^{1}$ Research plant pathologist.

${ }^{2}$ Corresponding author. E-mail: pat.wechter@ ars.usda.gov.
}

and PI 482252, were initially reported as resistant to Fon-R2 based on standard Fusarium assay definitions (Wechter et al., 2012). The term tolerance is now being used instead of resistance to characterize these two PIs and the lines described here. This decision is based on subsequent studies (data not shown) showing that after root or seed inoculation, the plants grow normally through fruit harvest without showing symptoms of wilt; however, the pathogen can be isolated from parts of the plant not directly associated with the site of inoculation.

\section{Origin}

Each of these lines is derived from a U.S. PIs of the wild type watermelon $C$. lanatus var. citroides collected in Zimbabwe and maintained at the USDA, ARS, Plant Genetic Resources and Conservation Unit, Griffin, GA. USVL246-FR2 and USVL252-FR2 are derived from PIs 482246 and 482252, respectively. In each case, tolerant individuals were selected from a greenhouse-based disease assay using a South Carolina Fon-R2 isolate. In our original greenhouse experiments, tolerance to Fon-R2 was significantly higher in these two PIs than in the watermelon cultivars Charleston Gray (moderately susceptible), Calhoun Gray (susceptible), and Sugar Baby (susceptible) that were used as the susceptible control lines, as well as in PI 296341-FR that was used as a Fon-R2resistant control (Wechter et al., 2012). In the original disease trials, several plants in each of the resistant PIs exhibited a lower level of tolerance to Fon-R2. Thus, we selected and self-pollinated the most tolerant plants from each PI in seven consecutive generations in the greenhouse, selecting for tolerance using a seed inoculation Fusarium assay described by Wechter et al. (2012) in each subsequent selfed population to produce $\mathrm{S}_{7}$ lines designated here as USVL246-FR2 and USVL252-FR2.

\section{Description and Performance}

USVL246-FR2 has a runner growth habit with an intermediate leaf blade type. Flowers are hermaphroditic. The fruits are round to slightly flattened (oblate), $\approx 25 \mathrm{~cm}$ in diameter and $20 \mathrm{~cm}$ in length (Fig. 1). The median fruit weight in field trials (five replications, six plants per plot) conducted in 2012

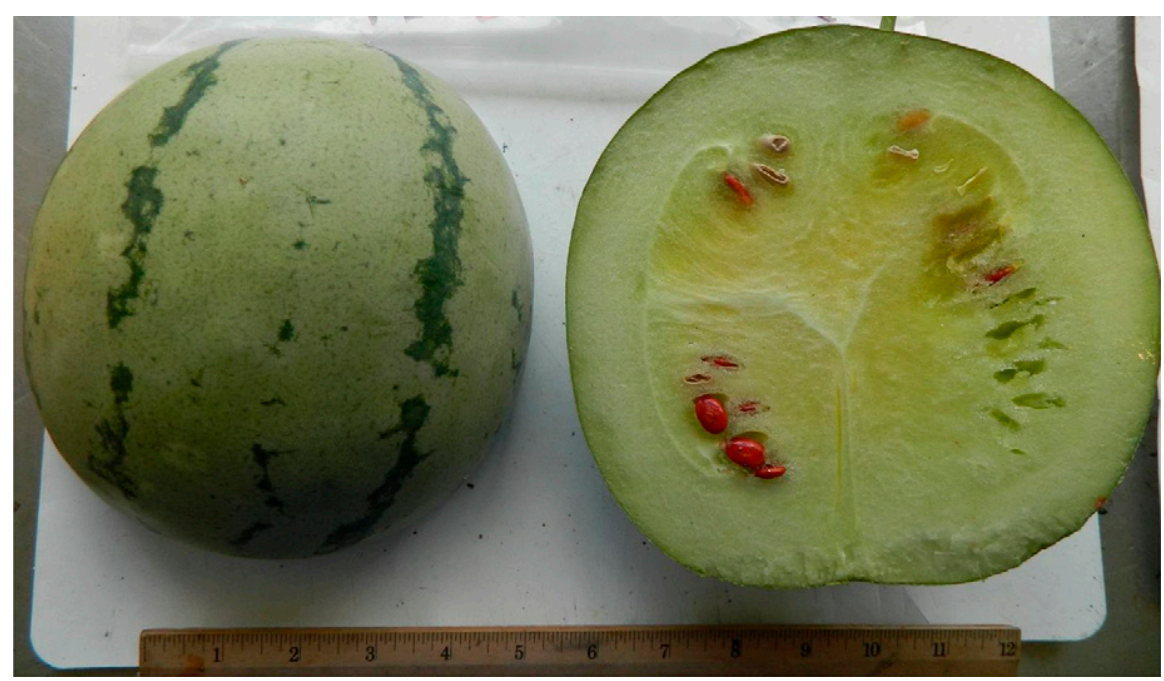

Fig. 1. A mature fruit of USVL246-FR2.

Table 1. Weights in kilograms of fruit raised to maturity in field trials during the summers of 2012 and 2013 at U.S. Vegetable Laboratory, Charleston, SC. Weights are averages and medians of all fruit from all plots in a six replication complete block trial with six plants per plot. Plants were grown on plastic mulch with under-plastic drip irrigation.

\begin{tabular}{|c|c|c|c|c|}
\hline & \multicolumn{2}{|c|}{ USVL246-FR2 } & \multicolumn{2}{|c|}{ USVL252-FR2 } \\
\hline & 2012 & 2013 & 2012 & 2013 \\
\hline Average & 8.59 & 4.86 & 1.07 & 1.08 \\
\hline SD & 2.22 & 2.32 & 0.56 & 0.61 \\
\hline Median & 8.66 & 5.20 & 1.00 & 0.94 \\
\hline
\end{tabular}


and 2013 was 8.7 and $5.2 \mathrm{~kg}$, respectively (Table 1). The predominant fruit rind color is light green, with a striped secondary skin color pattern. The stripes are dark green. Fruit flesh is firm and salmon yellow at maturity. The pericarp averages $4 \mathrm{~cm}$ thick and fruit bitterness is absent. Seeds are moderately large and red/orange in color. In Charleston, $\mathrm{SC}$, the fruit matures in $\approx 90-\mathrm{d}$ postanthesis. USVL246-FR2 seedlings are sturdy with large cotyledons and exhibit faster growth then the watermelon cultivars Charleston Gray, Allsweet, and Sugar Baby in our field trials. Fusarium wilt symptoms are noted in $\approx 15 \%$ of the $\mathrm{S}_{7}$ lines in greenhouse assays (Table 2), but are usually seen as a single wilted cotyledon (Fig. 2), with the plants often growing to maturity and producing fruit with no other symptoms. Greenhouse inoculation studies indicate USVL246-FR2 exhibits levels of tolerance to Fon-R2 similar to or higher than that exhibited by PI 296341FR, yet USVL246-FR2 exhibits more vigorous growth than PI 296341-FR. USVL246-FR2 crosses readily with the $C$. lanatus var. lanatus cultivars Charleston Grey, Calhoun Grey, and Sugar Baby.

USVL252-FR2 has a runner growth habit with an intermediate leaf blade type. Flowers are andromonoecious. The fruits are round to slightly broad, being $\approx 15 \mathrm{~cm}$ in diameter and $13-15 \mathrm{~cm}$ in length (Fig. 3). The median fruit weight in field trials (five replications, six plants per plot) conducted in 2012 and 2013 was 1.0 and $0.94 \mathrm{~kg}$, respectively (Table 1 ). The predominant fruit color is medium green, with a striped secondary skin color pattern. The stripes are light green. Fruit flesh is firm and white to salmon yellow at maturity. The pericarp averages $1.5 \mathrm{~cm}$ thick and fruit bitterness is absent. Seeds are pale red/orange in color. In Charleston, SC, fruits mature in $\approx 75$-d postanthesis. USVL252-FR2 seedlings are smaller than USVL246-FR2. Size and growth characteristics of USVL252-FR2 plants are similar to that of 'Charleston Gray', 'Allsweet', and 'Sugar Baby'. Fusarium wilt is noted in $\approx 10 \%$ of the $S_{7}$ plants of this line in greenhouse assays (Table 2), but it is usually seen as a single wilted cotyledon, with the plants often growing to maturity and producing fruit with no other symptom. Greenhouse inoculation studies indicate USVL252-FR2 has levels of tolerance to Fon-R2 similar to or higher than that found in PI 296341-FR, yet USVL252-FR exhibits more vigorous growth than PI 296341-FR. USVL252-FR2 crosses readily with the C. lanatus var. lanatus cultivars Charleston Grey, Calhoun Grey, and Sugar Baby.

\section{Availability}

Small quantities of seed of USVL246FR2 and USVL252-FR2 are available for distribution to interested research personnel and plant breeders who make written request to Dr. Patrick Wechter, U.S. Vegetable Laboratory, 2700 Savannah Highway, Charleston, SC 29414-5334 (Pat.Wechter@ars.usda.gov). Seed of USVL246-FR2 and USVL252-FR2
Table 2. Results of two separate Fusarium wilt assays (data combines as there was no statistical difference between tests) rated at 28-d post inoculation with Fusarium oxysporum f. sp. niveum race 2. Statistical analysis was performed using the Waller-Duncan K-ratio $t$ test $(P \leq 0.0001)$.

\begin{tabular}{lccc}
\hline Germplasm & Generation & Mean healthy $^{z}$ & Waller grouping $^{-}$ \\
USVL252-FR2 & $\mathrm{S}_{7}$ & 0.948 & $\mathrm{~A}$ \\
USVL246-FR2 & $\mathrm{S}_{7}$ & 0.861 & $\mathrm{~A}$ \\
296341-FR & $\mathrm{S}_{10}$ & 0.676 & $\mathrm{~B}$ \\
Charleston Grey & $\mathrm{NA}$ & 0.306 & $\mathrm{C}$ \\
Allsweet & $\mathrm{NA}$ & 0.269 & $\mathrm{C}$ \\
Sugar Baby & $\mathrm{NA}$ & 0.167 & $\mathrm{C}$ \\
\hline
\end{tabular}

${ }^{\mathrm{z}}$ Means are derived from three independent replications. Number of plants tested: USVL252-FR2 $(\mathrm{n}=$ 170), USVL246-FR2 $(n=131)$, 296341-FR $(n=165)$, Charleston Grey $(n=60)$, Allsweet $(n=60)$, and Sugar Baby $(\mathrm{n}=60)$.

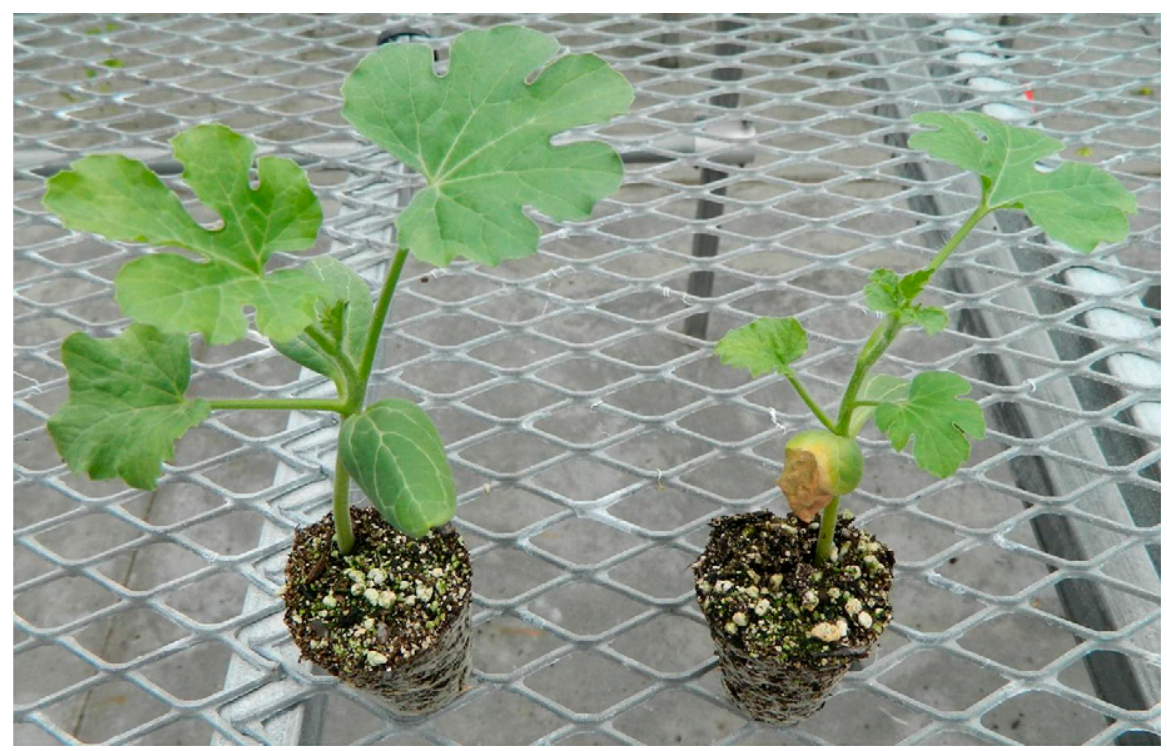

Fig. 2. Two 21-day-old USVL246-FR2 plants that were inoculated at the seed stage with $1 \times 10^{6} \mathrm{conidia} / \mathrm{mL}$ Fusarium oxysporum f. sp. niveum race 2 spore suspension. Plant on right shows a chlorotic/necrotic cotyledon but otherwise healthy plant. Symptomatic plant grew to maturity and produced fruit with no further symptoms.

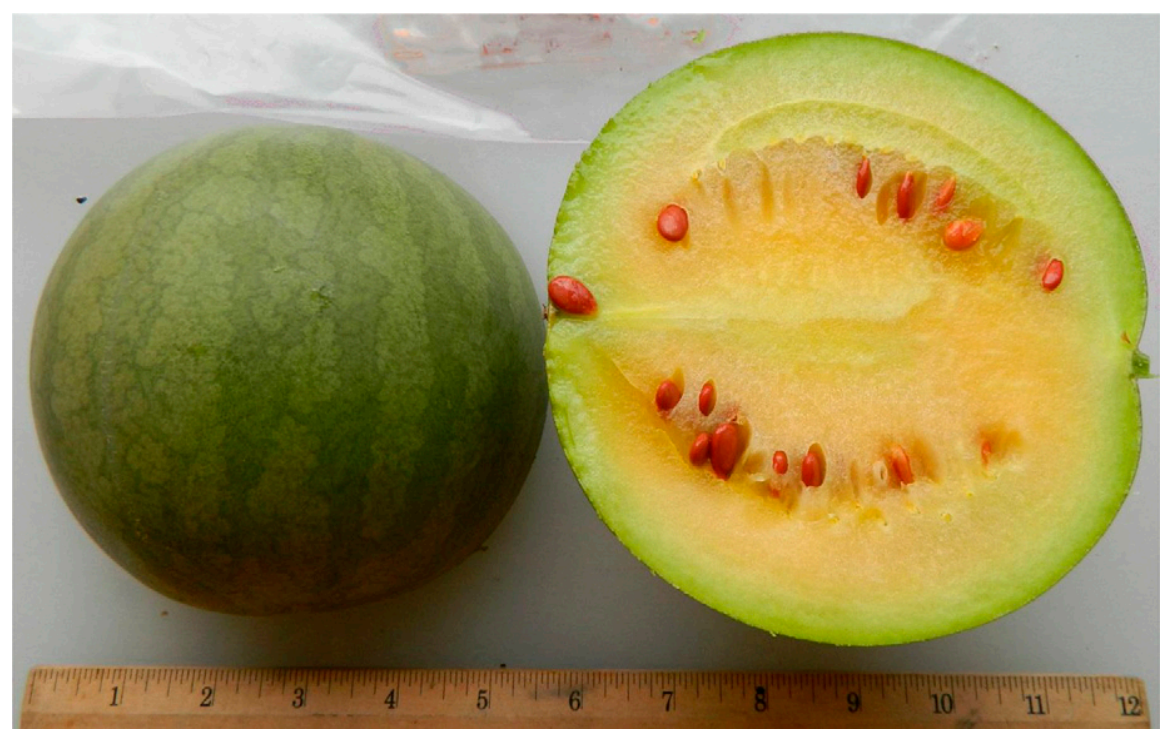

Fig. 3. A mature fruit of USVL252-FR2.

will also be submitted to the National Plant Germplasm System where it will be available for research purposes, including the development and commercialization of new, Fusarium wilt race 2-tolerant watermelon cultivars. It is requested that appropriate recognition of the source be given when this germplasm contributes to research or development of a new breeding line or cultivar. 


\section{Literature Cited}

Bruton, B.D., W.W. Fish, and D.D. Langston. 2008. First report of Fusarium wilt caused by Fusarium oxysporum f. sp. niveum race 2 in Georgia watermelons. Plant Dis. 92:983.

Bruton, B.D., C.L. Patterson, and R.D. Martyn. 1988. Fusarium wilt (Fusarium oxysporum f. sp. niveum race 2) of watermelons in Oklahoma. Plant Dis. 72:734.

Egel, D.S., R. Harikrishnan, and R.D. Martyn. 2005. First report of Fusarium oxysporum f. sp. niveum race 2, causal agent of Fusarium wilt of watermelon, in Indiana. Plant Dis. 89:108.

Keinath, A.P. and V.B. DuBose. 2009. First report of Fusarium oxysporum $\mathrm{f}$. sp. niveum race 2 in South Carolina watermelon fields. (Abstr.). Phytopathology 99:S63.

Keinath, A.P., R.L. Hassell, K.L. Everts, and X.-G. Zhou. 2010. Cover crops of hybrid common vetch reduce Fusarium wilt of seedless watermelon in the eastern United States. Online. Plant Health Prog., doi: 10.1094/PHP-2010-0914-01-RS.
Martyn, R.D. 1985. An aggressive race of Fusarium oxysporum $\mathrm{f}$. $\mathrm{sp}$. niveum new to the United States. Plant Dis. 69:1007.

Martyn, R.D. 1987. Fusarium oxysporum f. sp. niveum race 2 : A highly aggressive race new to the United States. Plant Dis. 71:233-236.

Martyn, R.D. and B.D. Bruton. 1989. An initial survey of the United States for races of Fusarium oxysporum f. sp. niveum. HortScience 24:696-698.

Martyn, R.D. and D. Netzer. 1991. Resistance to races 0,1 , and 2 of Fusarium wilt of watermelon in Citrullus sp. PI-296341-FR. HortScience 26:429-432.

Netzer, D. 1976. Physiological races of soil population levels of Fusarium wilt of watermelon. Phytoparasitica 4:131-136.

Netzer, D. and R.D. Martyn. 1989. PI 296341, a source of resistance in watermelon to race 2 of Fusarium oxysporum $\mathrm{f}$. sp. niveum. Plant Dis. 73:518.

Bruton, B.D. and J.P. Damicone. 1999. Fusarium wilt of watermelon: Impact of race 2 of
Fusarium oxysporum f. sp. niveum on watermelon production in Texas and Oklahoma. Subtrop. Plant Sci. 51:4-9.

Wechter, W.P., C.S. Kousik, M.L. McMillan, and A. Levi. 2012. Identification of resistance to Fusarium oxysporum f. sp. niveum race 2 in Citrullus lanatus var. citroides plant introductions. HortScience 47:334-338.

Zhou, X.G. and K.L. Everts. 2001. First report of the occurrence of Fusarium oxysporum f. sp. niveum in commercial watermelon production areas of Maryland and Delaware. Plant Dis. $85: 1291$.

Zhou, X.G. and K.L. Everts. 2003. Races and inoculum density of Fusarium oxysporum $\mathrm{f}$. sp. niveum in commercial watermelon fields in Maryland and Delaware. Plant Dis. 87:692698.

Zhou, X.G., K.L. Everts, and B.D. Bruton. 2010. Race 3, a new and highly virulent race of Fusarium oxysporum f. sp. niveum causing Fusarium wilt in watermelon. Plant Dis. 94: 92-98. 